archives-ouvertes

\title{
Characterization Shear Properties of PVC Foams Instrumented by Optical Fiber under Flexural Loading
}

Karim Mharsi, Xavier Chapeleau, Jamal Fajoui, Amira Sellami, Pascal

Casari, Mohamed Kchaou

\section{To cite this version:}

Karim Mharsi, Xavier Chapeleau, Jamal Fajoui, Amira Sellami, Pascal Casari, et al.. Characterization Shear Properties of PVC Foams Instrumented by Optical Fiber under Flexural Loading. Journal of Testing and Evaluation, ASTM International, 2021, 49 (4), pp.2507-2517. 10.1520/JTE20200123 . hal-03284231

\section{HAL Id: hal-03284231 \\ https://hal.inria.fr/hal-03284231}

Submitted on 12 Jul 2021

HAL is a multi-disciplinary open access archive for the deposit and dissemination of scientific research documents, whether they are published or not. The documents may come from teaching and research institutions in France or abroad, or from public or private research centers.
L'archive ouverte pluridisciplinaire HAL, est destinée au dépôt et à la diffusion de documents scientifiques de niveau recherche, publiés ou non, émanant des établissements d'enseignement et de recherche français ou étrangers, des laboratoires publics ou privés. 
Characterization shear properties of PVC foams instrumented by optical fiber under flexural loading

\author{
Karim MHARSI ${ }^{1,4^{*}}$, Xavier CHAPELEAU ${ }^{2}$, Jamal FAJOUI ${ }^{1}$, Amira SELLAMI ${ }^{4}$, Pascal \\ CASARI ${ }^{1}$, Mohamed KCHAOU 3,4 * \\ ${ }^{1}$ Institut de recherche en génie civil et mécanique (GeM) (UMR, CNRS 6183), Université de Nantes, Centrale Nantes \\ ; 58, rue Michel Ange-BP 420, 44600 Saint-Nazaire Cedex, France \\ ${ }^{2}$ Institut français des sciences et technologies des transports, de l'aménagement et des réseaux (IFSTTAR - Nantes) \\ Route de

\begin{abstract}
The bending behavior of foam core sandwich composites has increasingly attracted attention and application in industries such as shipbuilding, aircraft and wind turbine industries. The main objective of this research work is the assessment of shear strain in a foam core beam by means of optical fiber sensors during bending test. Experimental studies were conducted on a PVC foam beam in which three optical fibers were embedded in a longitudinal plane across the thickness of the foam core; straight optical fibers measure strains due to the tension/compression load, whereas the sinusoidal fibers catch strains due to the shear load. Finite element model (FEM) was used to predict strain levels in order to validate and explain optical fiber sensor measurements from 3- and 4-point bending tests. The concordance of the shear properties identified by optical-fiber sensor results and obtained by finite element simulation was evaluated to validate the new developed technique of characterization. Results shows good agreement between the experimental and numerical responses.
\end{abstract}

Keywords: PVC foam beam; optical fiber sensor; bending test; shear strain measurement; Finite element model 


\section{Introduction}

PVC foam is widely used in several industrial fields alone or integrated between two skins in the form of a sandwich structure. These are increasingly used in marine constructions, namely submarines, ships, and boats, thanks to their important properties for composites used in these applications, among which lightweight and high damage tolerance can be mentioned [1]. On the other hand, determining the distribution of deformations on sandwich structures is much more complicated than monoblock metal structures because of their fragility and their anisotropic characteristics [2]. In fact, there are many types of sandwich panels, but the principle is always the same, i.e. to place a light and rigid material in compression and shear, which is the core, between two skins that bear great bending loads. In this way, we obtain a light and stiff structural material. Since this type of structure has a very broad field of research and large applications, the modification of their composition and their architecture makes it possible to improve their mechanical and physical properties.

Therefore, the determination of the mechanical properties of composite structures is a necessity for the dimensioning of boats. Gibson [3] has demonstrated that the determination of these properties should take into account different possible damage criterions. Nevertheless, foam shear failure, skin failure and compression / tensile damage were found to be the most common flexural failure mode for sandwich panels [4]. In fact, the foam of sandwich material must have enough shear rigidity and strength so as the overall sandwich buckling, excessive deflection and shear failure will not befall under design loads. It has been shown that significant shear deformation should be considered in the total deflection of sandwich structures under bending loads [5].

Several researchers have reported in-situ measurement techniques [6] such as conventional electrical resistance strain gauges which have been widely used to monitor and identify the strain value in the core of sandwich. Nonetheless, limitations pertaining to cost, installation time and physical complexity have been found. To overcome these limitations, the development of novel techniques for strain measurement in the foam core of sandwich structure has emerged. Recently, the experimental analysis of the material behavior has been undertaken using a strategic embedment of optical Fiber Bragg Gratings (FBG) sensors endowed with the particularities of small size, electromagnetic immunity, and higher thermal resistance. 
In fact, advanced optical fiber detection techniques, such as the FBG [7-8-9], also have obvious weaknesses, including limited monitoring of the constraint location range. These deficiencies prevent the accurate determination of the location of the first damage and prevent association of local damage mechanisms with the overall conditions of the structure [10]. This limit is overcome by distributed optical fiber sensors (DOFS).

The challenge of the use of distributed optical fiber as a substitute of traditional distinct point sensors is that it can record online and continuous temperature and strain as a function of position along the whole sensing-fiber length [11]. DOFS technology is able to measure distributed strains on the basis of the backscattered light properties [12]. The major backscatter types are likely to be used for the measurement of distributed strains: Raman, Rayleigh and Brillouin [13]. Concerning Raman, although it is used to measure just temperature, it cannot measure strain. For a $10-\mathrm{mm}$ spatial resolution, it can have a sensing range of $1 \mathrm{Km}$, and for $17-\mathrm{m}$ spatial resolution, it can measure up to $37 \mathrm{Km}$ [14]. As for Rayleigh backscatter, it offers more elevated spatial and strain resolution readings, which is suitable for monitoring localized strain changes over relatively short distances [15]. There have been several implementations of distributed strain detection based on Rayleigh backscattering in other types of materials as well. [16-17]. Based on Rayleigh scattering, the acquisition system can supply not only static but also dynamic measurements with sampling rates up to $250 \mathrm{~Hz}$ on detection lengths up to $20 \mathrm{~m}$ [18]. With respect to Brillouin backscatter sensors, they function by the measurement of the light frequency reflected along the fiber [19]. This sensing range is ideal for large structure: spatial resolution up to $1 \mathrm{~m}$ and strain precision up to $30 \mu \varepsilon[20]$.

However, this technique is not frequently used for damage detection in composite structure. To the best of our knowledge, no research work has ever used distributed strain sensing to determine whether the strains can be used to evaluate the behavior of composite structure. Persistent research efforts have been made to completely mature the technology via laboratory, physical models, and in-situ tests. High-resolution optical backscatter reflectometry (OBR) has become a prized tool in composite's test and diagnostics. The application of distributed optical fiber sensors to evaluate strain distribution on a sandwich foam beam has not yet been conducted. Significant advances have been made in recent years in the use of the Brillouin optical time-domain reflectometer (BOTDR) optical fibers to measure strains [21]. The aim of this research is to assess the suitability of the OBR 
distributed optic fiber technology as an alternative to conventional electrical resistance foil strain gauges for the measurement of strains on 3 and 4 points bending test. The understanding of such a phenomenon on a foam sandwich beam would enable OBR to become a performant strain sensing technique for sandwich materials.

\section{Specimen definition}

Specimens were made with a foam core Airex C70 - $200 \mathrm{~kg} / \mathrm{m}^{3}$ (thickness $=48 \mathrm{~mm}$ ) and instrumented by fiber optic sensors. To integrate these sensors in the core of the sandwich panel, the foam block was firstly cut in half lengthwise. Table 1 presents the mechanical properties of the PVC used in the sandwich structure extracted from the supplier's technical sheet.

Table. 1. Mechanical properties of PVC

\begin{tabular}{|c|c|c|c|c|}
\hline \multicolumn{2}{|c|}{$\mathbf{E}$ (MPa) } & $\boldsymbol{v}$ & $\mathbf{G}(\mathbf{M P a})$ & $\boldsymbol{\alpha}\left(\mathbf{K}^{-\mathbf{1}}\right)$ \\
\hline Average & 175 & \multirow{2}{*}{0,4} & 70 & \multirow{2}{*}{$438710^{-8}$} \\
\cline { 1 - 3 } Minimum & 140 & & 68 & \\
\hline
\end{tabular}

As shown in figure 1, two optical fibers were arranged in parallel $3 \mathrm{~mm}$ from each edge of the test specimen. A third optical fiber has been placed sinusoïdally with a slope. After gluing the 3 optical fibers, the 2 pieces of foam were assembled with an epoxy adhesive paste of high strength and toughness (Huntsman Araldite 420). The resin/hardener mix was spread over the joint with a spatula at room temperature and allowed to dry for 24 hours.

The joint of the separated foam blocks should be brought together and fastened immediately after the application of the adhesive. A smooth contact pressure all over the joint area will guarantee optimum cure. The final dimensions of the specimen are $800 \times 250 \times 48 \mathrm{~mm}$.

Fig. 1. Embedding optical fibers between two foam blocks

\section{Description of optical fiber sensors and measurement technology}

Distributed fiber-optic sensors are able to provide a distributed strain / temperature measurement and profile over the optical fiber length, thus their significance in large

- $\quad$ structures $[16,17]$. In fact, instrumentation with an optical fiber sensor involves implanting the 
optical fibers into the structure, configuring the sensor, interrogating the specimen to acquire the information values, and finally processing and interpreting the data.

Optical fiber is a waveguide that exploits the refractive properties of light. It usually consists of a core surrounded by a sheathing cover. The fiber core has a faintly higher refractive index (difference of some thousandths) than the sheath and thus can confine light that is entirely reflected several times at the interface between the two materials (caused by the of total internal reflection phenomenon). The gathering is generally covered with a protective plastic sheath.

An optical fiber sensor is therefore a measuring device in which the optical fiber acts as a detector for transporting the light signal. It is generally made up of a light emitter (source), an optical fiber, an optical detection device, and one or more photodiodes responsible for collecting the signal, which are followed by an acquisition chain (fig. 2).

Fig. 2. Interrogation with optical fibers

One of the main advantages of this method is that the fibers can be embedded inside the material unlike other techniques such as Digital Image Correlation (DIC) which can only determine deformations on the surface. In this work, "ODiSI-B Luna" machine is chosen to make the acquisition. The measurement protocol of this machine is described in figure 3 . This machine simultaneously interrogates hundreds of detection locations per meter on a single optical fiber at a speed of up to $250 \mathrm{~Hz}$.

Fig. 3. Description of the measurement protocol

Embedding the optical fibers helps in measuring the strains due to the bending moment and the shear during static bending tests. Indeed, the two straight optical fibers are sensitive to the longitudinal deformations of the specimen. The undulating optical fiber can measure alternately the deformations caused by:

- The bending moment near the upper and lower surfaces of the test piece.

- The shearing when at the center of the specimen it crosses the neutral axis with a slope of $45^{\circ}$. 
Fig. 4. The optical fibers inserted on the foam of sandwich

Figure 4 presents the two red optical fibers that are straight and measure strains varying slowly with the bending moment. The third optical fiber is undulating to get strains due to bending moments and shear forces when it is located near the faces or in the middle, respectively. It follows a sinusoidal curve (Equation (1)) with $20 \mathrm{~mm}$ of amplitude, a period of $126 \mathrm{~mm}$ and crosses the middle of the thickness with an angle of $45^{\circ}$. The path of the optical fiber with origin of $\mathrm{x}$ axis in the middle of the specimen is:

$$
y(x)=20 \sin \frac{2 \pi x}{126}
$$

The optical fiber runs along six periods along the neutral axis.

\section{Experimental setup and procedure}

To study the bending behavior of the PVC foam beam and to confirm the use of (OBR) optical fibers for sandwich materials, it was necessary to go through the 3-point and 4-point symmetric and asymmetrical bending study. These types of loading make it possible to analyze the mechanical properties in tension, compression, shearing and moment. All the following bending tests are carried out according to ASTM C393 standard [22].

\subsection{Three bending test}

The force is applied in the middle of the test specimen at $\mathrm{x}=400 \mathrm{~mm}$. The two bending supports are located at $\mathrm{x}_{1}=100 \mathrm{~mm}$ and $\mathrm{x}_{2}=700 \mathrm{~mm}$. Figure 5 summarizes the 3-point bending test. The set is equipped with two force sensors to measure the load applied to the sample.

Fig. 5. Three bending test on the core specimen

\subsection{Four bending test}

For the four-point bending test, two vertical forces are applied with two bending supports (fig. $6)$. The action points are located at $\left(\mathrm{x}_{1}=100, \mathrm{x}_{2}=300, \mathrm{x}_{3}=500, \mathrm{x}_{4}=700 \mathrm{~mm}\right)$. 
- Four-point bending test (noted 4A): symmetrical loading

- Four-point bending test (noted 4B): asymmetrical loading

\author{
Symmetrical four-point bending test 4A Asymmetrical four-point bending test 4B
}

Fig. 6. Four bending test on the core specimen

\title{
5. Numerical model
}

Referring to [1-3], a need for in-situ measurement techniques is expressed. That is why this work continues towards the development of novel techniques for strain measurement in the foam core of sandwich structure. During bending tests, the straight optical fibers measure strains due to the bending moment, whereas the sinusoidal one measures strains due to the shear load.

The model is built on ABAQUS ${ }^{\circledR}$ according to the boundary conditions mentioned in parts 4.1 and 4.2. The material behavior is considered as linear and elastic. C3D8R element type (8node linear brick, reduced integration, hourglass control) was used. A mesh convergence study was carried out, and 24000 elements were fixed for our simulations with 100 elements on $\mathrm{x}$-coordinate, 6 on y-coordinate and 40 on z-coordinate. The used properties are given in Table 1.

For the straight optical fibers, we can directly compare the numerical and experimental results, but it is not the case for the undulated one. Indeed, strains from the experiment are given along the optical fiber. Comparable values with the test need to be calculated from the model results. The calculation of strains is conducted along the sinusoidal path. From equation (1), we can calculate the derivative.

$$
\frac{\partial y}{\partial x}=\cos \frac{2 \pi x}{126} \text { which is the slope of the tangent }
$$

The tangent vector along the path and its components are deduced and noted as indicated in equation (3). 


$$
n=\left(\begin{array}{c}
n_{x} \\
0
\end{array}\right) \text { with } n_{x}=\frac{1}{\sqrt{1+\left(\frac{\partial y}{\partial x}\right)^{2}}} ; n_{y}=\frac{\left(\frac{\partial y}{\partial x}\right)^{2}}{\sqrt{1+\left(\frac{\partial y}{\partial x}\right)^{2}}}
$$

The value of the strain to be compared to the optical fiber response is given by equation (4).

$$
\varepsilon_{t}=n^{T} \cdot \varepsilon \cdot n=n_{x}^{2} \varepsilon_{x x}+2 n_{x} n_{y} \varepsilon_{x x}+n_{y}^{2} \varepsilon_{y y}
$$

\section{Results and discussions}

One of the main methods to evaluate the performance of foam sandwich core under static load conditions is bending test. Finite element codes allowing simulations under these static conditions are performed. The calculations of the three-dimensional static finite element were conducted using ABAQUS software to simulate the tests.

The numerical simulation deals with strain distribution, applying information relative to a three-point-bending test. Figure 7 illustrates deformed foam beam for each bending test predicted by finite element simulations. It is obvious that simulations results include the shearing of the PVC foam beam core, the compression of the upper part of the beam and the tension of its lower part.

Fig. 7. Distribution of stresses on the PVC foam beam:

a) 3-point bending b) 4-point bending $\mathrm{A}$ c) 4-point bending $\mathrm{B}$

Fig. 8. Distribution of the deformations $\varepsilon_{\mathrm{xx}}$ in the section of the test specimen at $\mathrm{x}=400 \mathrm{~mm}$ for the 3-point bending test

Fig. 9. Variation of the distribution of the $\varepsilon_{\mathrm{xx}}$ deformations in the section for a 3-point bending test 
The deformation values are almost uniform over the section. Figures 8 and 9 show the distribution of the $\varepsilon_{\mathrm{xx}}$ deformations for the 3-point bending test as an example. The difference between the curves for the 3 paths could be negligible. Then, the hypothesis of plane strains could be applied with a 2D model to lighten the finite element model.

To achieve our goal and to prove the efficiency of OBR optical fiber for bending tests, the numerical and experimental results are compared. Numerical strains are taken from the same positions of the actual fibers. Figure 10.a shows that the experimental strain result caused by the three bending tests is faithfully reproduced in the simulation with the straight optical fibers. For this first application, the agreement is good, which is a sign of a good bonding all along the fibers. Besides, the relative difference between the two maximum values at $\mathrm{x}=400 \mathrm{~mm}$ between the experimental and the numerical results for the 3-point bending test, for example, does not exceed $1 \%$. The strains magnitude already reached \pm 2000 microstrains without failure for 3-point bending test, 600 microstrains for $4 \mathrm{~A}$ bending test and \pm 900 microstrains for $4 \mathrm{~B}$ (fig. 10.b and fig. 10.c). In fact, taking into account that the optical fiber OBR is placed at the top and the bottom of the foam, respectively, the negative values treat the deformation caused by the compression of the upper part of the beam and the positive values represent the deformation values caused by the tension of the beam of the lower part of the beam.

Fig. 10. Strain components located along the straight optical fiber a) 3-point bending, b) 4-point bending A c) 4-point bending $\mathrm{B}$

The main mode of collapse identified for the core beam in three-point and four-point bending is shear. This mode of core sandwich beam failure has been confirmed by numerous studies, including those of Chen et al. [23] and Craig et al. [24]. Obviously, the core is primarily selected to carry shear loading. For bending tests, undulating OBR optical fibers are used to evaluate shear strain distribution. In fact, in the zone of strain gradient and given the high rigidity of the optical fiber (74 $000 \mathrm{MPa}$ ) and the epoxy adhesive $(2500 \mathrm{MPa})$ compared with the low rigidity of the foam, it is obvious that, at this level, the strong gradient, the optical fiber cannot experimentally record the true values of strain. Furthermore, the intrusive nature of the optical fiber causes disturbances in the results. Since in our study, we are interested in the shear behavior of the core in the case of undulating OBR optical fiber, the result from the FEM (fig. 11) has been transformed as a tangent strain along the path, and by calculating the 
curvilinear abscissa as well. At each point along the path of the optical fiber, a set of strains is given by the model. The shear strain is low compared to the other components. This is typical to the behavior of a homogeneous beam.

Fig. 11. Strain components located along the optical fiber.

As it is shown in the bending curves and for the three different tests (fig. 12), it is clear that the linear part representing the evolution of the deformation caused by the shear in the foam is well correlated with that found by the simulation using ABAQUS software. This result confirms the effectiveness of an optical sensor integrated in a sandwich foam for studying the shear behavior of the foam. On the other hand, it is noted that the level of the deformation at the maximum points of the path is weak. Normally, the deformation in these points must be equal to that given by the right optical fibers. There is a factor of two between the values of the sinusoidal optical fiber and those given by one of the two straight optical fibers, which is due to the intrusive nature of fiber optics.

Fig. 12. Strain components located along the undulated optical fiber a) 3-point bending test b) bending $4 \mathrm{~A}$ test and c) bending $4 \mathrm{~B}$ 


\section{Conclusion}

In this paper, the bending behavior of the PVC core of a sandwich structure was investigated using bending tests. The following conclusions were drawn:

i. The straight and undulated fibers showed good agreement between the experimental and numerical responses. It has been clearly demonstrated that the numerical analyses and experiments have confirmed the use of OBR optical fiber in the investigation of the foam core behavior when different boundary conditions are imposed.

ii. The sandwich material is first and foremost a complex structure whose bending failure is controlled by the behavior of the foam, which is governed by the tensioncompression of the two lower and upper parts of the foam and further shearing of the core of the foam.

iii. This study allowed us to trace all the behavior of the foam using three OBR optical fibers in specific locations. Therefore, it was possible to validate the use of distributed fiber optic strain measurements on the foam of sandwich structure.

iv. The hypothesis of plane strains could be used to switch to a $2 \mathrm{D}$ model. On the other hand, we will not be able to take into account the phenomenon of intrusivity of the optical fiber, which we intend to study in our future research. 


\section{References}

[1] T.A. Schaedler, W.B. Carter Architected cellular materials, Annual Review Mater Res, 46 (2016): 187-210, https://doi.org/10.1146/annurev-matsci-070115-031624.

[2] H. Kilic, R. Hajali, Progressive damage and nonlinear analysis of pultruded composite structures Compos. Part B Eng., 34 (2003): 235-250, http://doi.org/10.1016/ S1359-8368(02)00103-8.

[3] R.F Gibson, Principles of Composite Material Mechanics, Third Edition CRC Press (2011).

[4] C.A. Steeves, N.A Fleck, Collapse mechanisms of sandwich beams with composite faces and a foam core, loaded in three-point bending. Part I: analytical models and minimum weight design. Int. J. Mech. Sci., $46 \quad$ (2004): 561-583, https://www.doi.org/10.1016/j.ijmecsci.2004.04.004.

[5] E.J Barbero. Introduction to Composite Materials Design, Second Edition, CRCPress, 2010.

[6] A. RUSSO, B. ZUCCARELLO, Experimental and numerical evaluation of the mechanical behavior of GFRP sandwich panels. Compos. Struct., 81 (2007): 575-586, https://www.doi.org/10.1016/j.compstruct.2006.10.007.

[7] P. Ferdinand, Réseaux de capteurs à fibres optiques - Applications, Techniques de l’Ingénieur, Référence R461, 2008.

[8] R. Regier, N.A. Hoult, Distributed strain behavior of a reinforced concrete bridge: case study. J Bridge Eng, 19 (12) (2014), 1-8, https://doi.org/10.1061/

(ASCE)BE.1943-5592.0000637.

[9] D. Grobnic, S.J. Mihailov, C.W. Smelser, R.B. Walker, Multiparameter sensor based on single high-order fiber Bragg grating made with IR-Femtosecond radiation in singlemode fibers. IEEE Sens. J., 8 (2008): 1223-1228, https://doi.org/10.1109/JSEN.2008.926186.

[10] O. EBRAHIM, R. GINU, P. GANGADHARA, Thermal sensitivity and relaxation of carbon fibre-foam sandwich composites with fibre optic sensors. Journal of Sandwich Structures and Materials. (2016), https://www.doi.org/10.1177/1099636216647929.

[11] P. Ferdinand, The Evolution of Optical Fiber Sensors Technologies During the 35 Last Years and Their Applications in Structure Health Monitoring. In Proceedings of the EWSHM-7th European Workshop on Structural Health Monitoring, Nantes, France, (2014): 8-11, https://perma.cc/ZH5Y-PKRV.

[12] R. Di Sante, Fibre Optic Sensors for Structural Health Monitoring of Aircraft Composite Structures: Recent Advances and Applications (2015), 18666-18713, https://doi.org/10.3390/s150818666. 
[13] J. He, J. Yang, Y. Wang, H. Waisman, W. Zhang, Probabilistic Model Updating for Sizing of Hole-Edge Crack Using Fiber Bragg Grating Sensors and the High-Order Extended Finite Element Method. (2016), 16, 1956, http://doi.org/10.3390/s16111956.

[14] A. Deif, B. Martín-Pérez, B. Cousin, C. Zhang, X. Bao, W. Li, Detection of cracks in a reinforced concrete beam using distributed Brillouin fibre sensors. Smart Mater. Struct. (2010), 19, 055014, http://doi.org/10.1088/0964-1726/19/5/055014.

[15] M. Niklès, Fibre optic distributed scattering sensing system: perspectives and challenges for high performance applications, Proc. SPIE 6619, Third European Workshop on Optical Fibre Sensors, 66190D, 2007, http://doi.org/10.1117/12.738349.

[16] L. Schenato, A Review of Distributed Fibre Optic Sensors for Geo-Hydrological Applications, Appl. Sci. (2017), 7, 896, https://doi.org/10.3390/app7090896.

[17] M.G. Tanner, S. D. Dyer, B. Baek, R. H. Hadfield, S. W. Nam, High-resolution singlemode fiber-optic distributed Raman sensor for absolute temperature measurement using superconducting nanowire single-photon detectors, Appl. Phys. Lett. 99, 201110, 2011, https://doi.org/10.1063/1.3656702.

[18] J. Park, G. Bolognini, D. Lee, P. Kim, P. Cho, F.Di Pasquale, et al. Raman-based distributed temperature sensor with simplex coding and link optimization

$\begin{array}{llllll}\text { IEEE Photonics } & \text { Technol } & \text { Lett, } & 18 & \text { (2006): }\end{array}$ http://doi.org/10.1109/LPT.2006.881239.

[19] H. S. Pradhan, P. K. Sahu, A survey on the performances of distributed fiber-optic sensors, 2015 International Conference on Microwave, Optical and Communication Engineering (ICMOCE), Bhubaneswar, 243-246, https://doi.org/10.1109/icmoce.2015.7489736.

[20] X. Bao AND L. Chen, Recent progress in distributed fibre optic sensors, Sensors, vol. 12, (2012) 8601-8639, http://doi.org/10.3390/s120708601.

[21] J.M. Henault, M. Quiertant, S. Delepine-Lesoille, J. Salin, G. Moreau, F. Taillade, et al. Quantitative strain measurement and crack detection in RC structures using a truly distributed fiber optic sensing system, Constr Build Mater, 37 (2012) 916-923, https://perma.cc/FR2HZNPK.

[22] ASTM C393 / C393M - 11e1 Standard test method for core shear properties of Sandwich Constructions by Beam Flexure, American Society for Testing and Materials (2008), http://doi.org/10.1520/C0393_C0393M-16.

[23] Chen C, Fleck N. A creep model for polymeric foams. Technical Report CUED/C MICROMECH/TR.32, Cambridge Centre for Micromechanics, University of Cambridge, 2000, https://doi.org/10.1177/1099636212449851.

[24] Craig A. Steeves, Norman A. Fleck Collapse mechanisms of sandwich beams with composite faces and a foam core, loaded in three-point bending. Part II: experimental investigation and numerical modelling, International Journal of Mechanical Sciences 46 (2004) 585 - 608, https://doi.org/10.1016/j.ijmecsci.2004.04.004. 


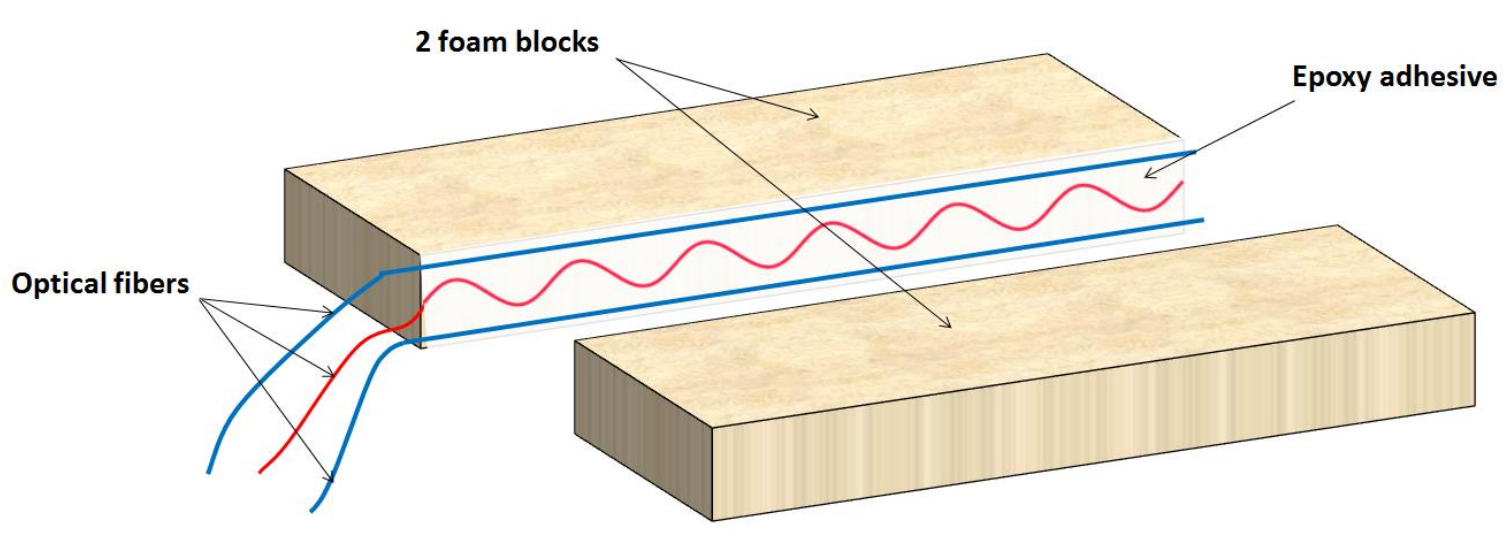

Fig. 1. Embedding optical fibers between two foam blocks 


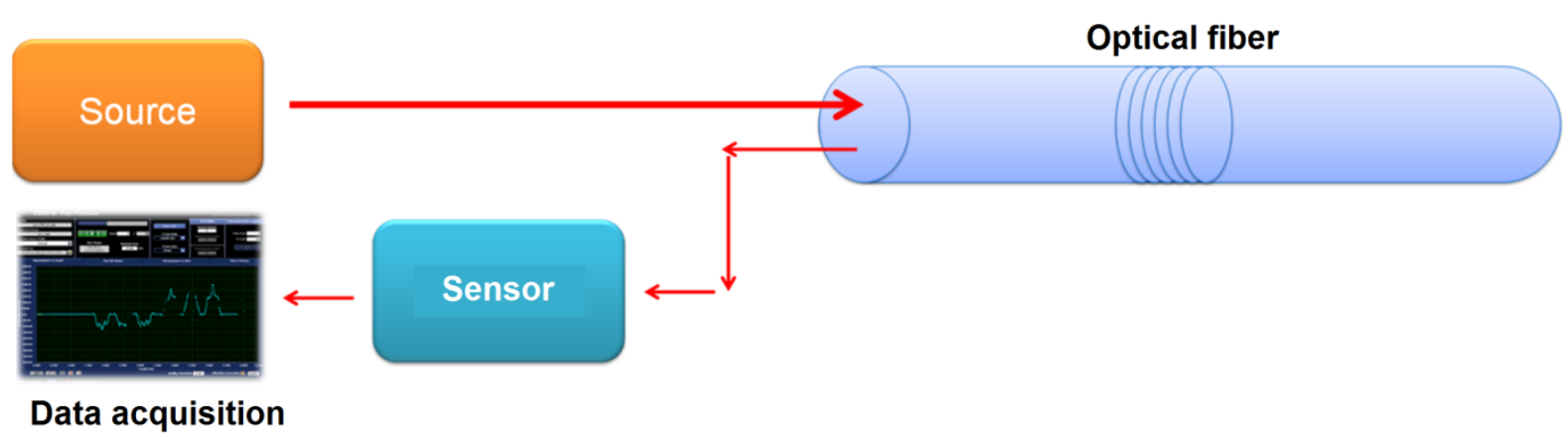

Fig. 2. Interrogation with optical fibers

16
17
18
19
20
21
22
23
24
25
26
27
28
29
30
31
32
33
34
35
36
37
38
39
40
41
42
43
44
45
46
47
48
49
50
51
52
53
54
55
56
57
58
59
60




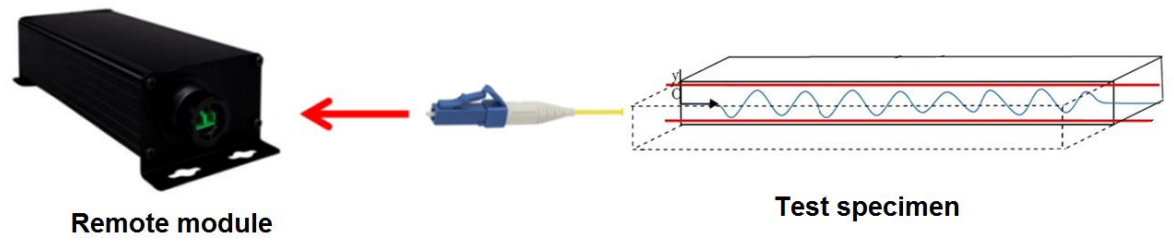

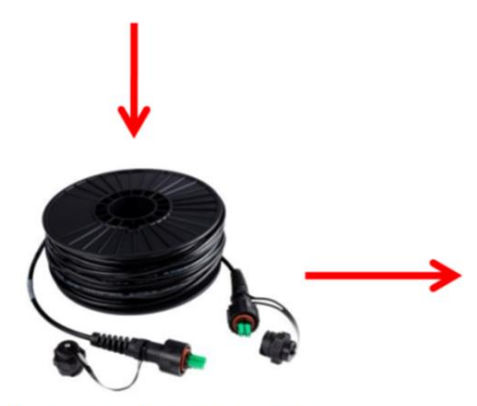

50 meter extension cable

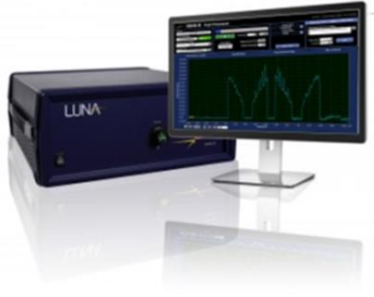

Distributed optical sensor interrogator

Fig. 3. Description of the measurement protocol 
Two foam blocks



Fig. 4. The optical fibers inserted on the foam of sandwich 

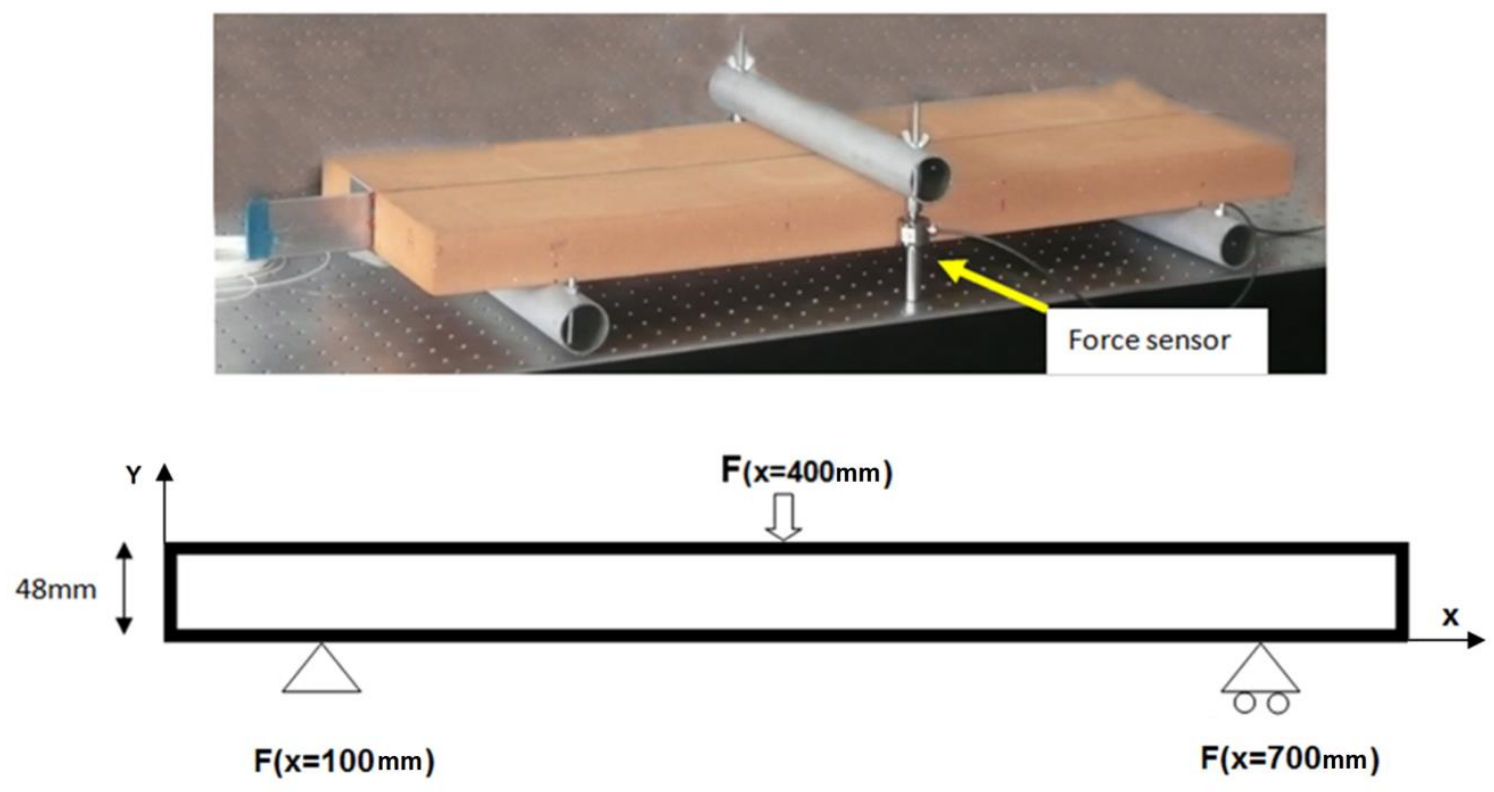

Fig. 5. Three bending test on the core specimen 

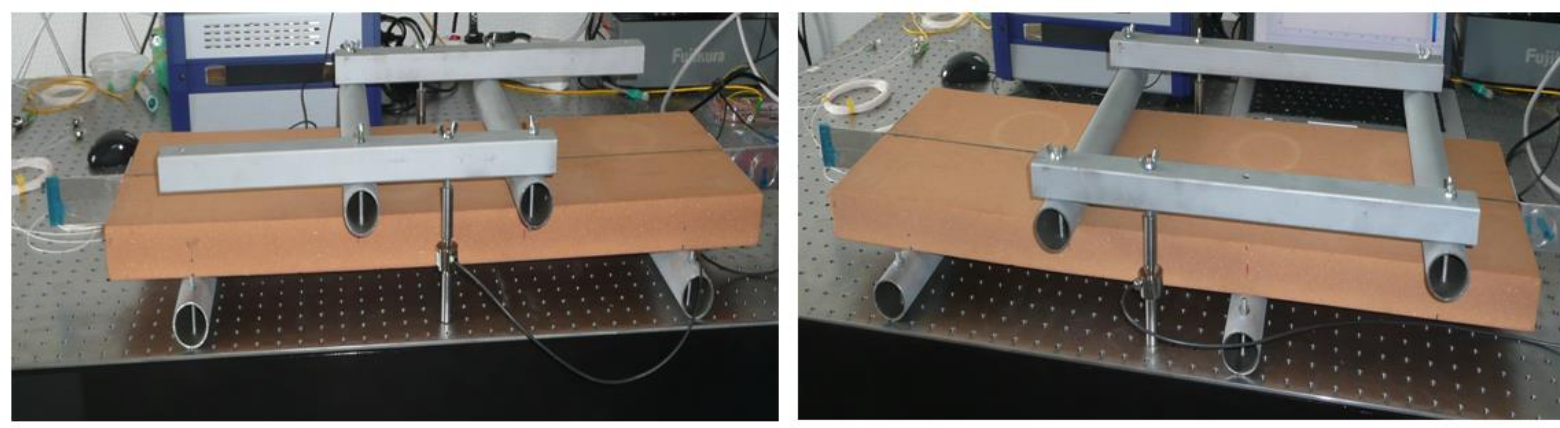

Symmetrical four-point bending test 4A Asymmetrical four-point bending test 4B

Fig. 6. Four bending test on the core specimen 
a)

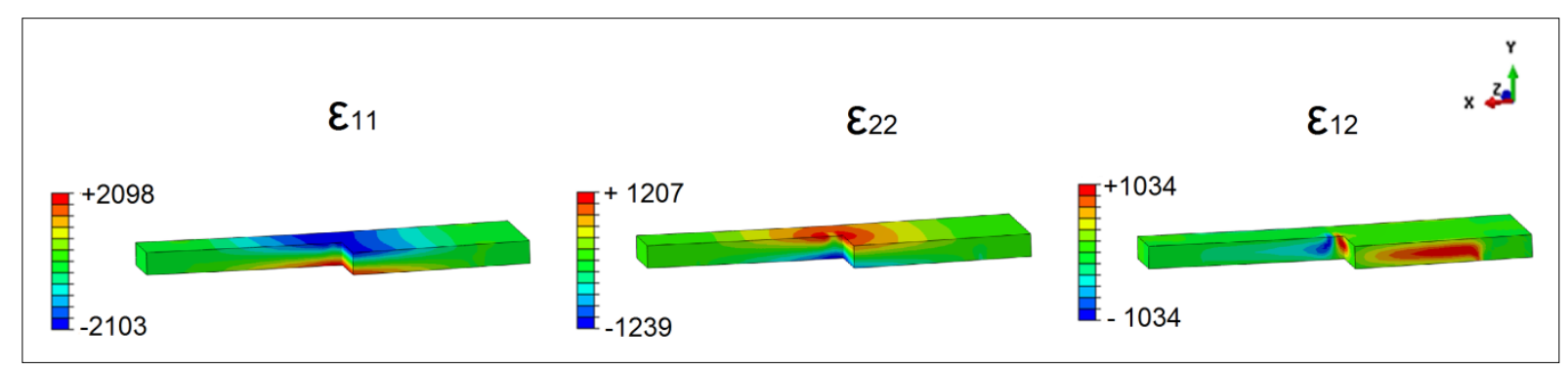

b)

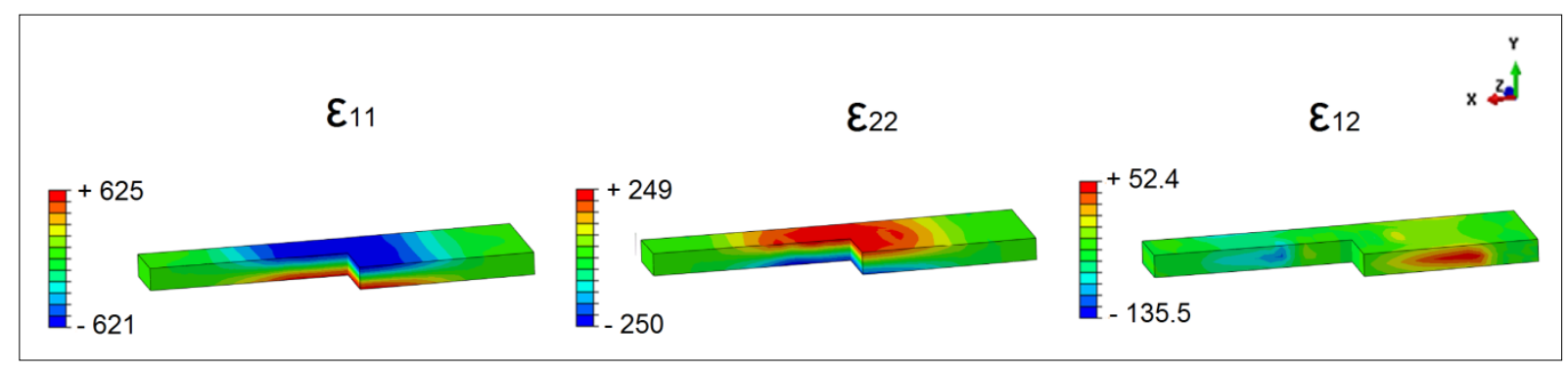

C)

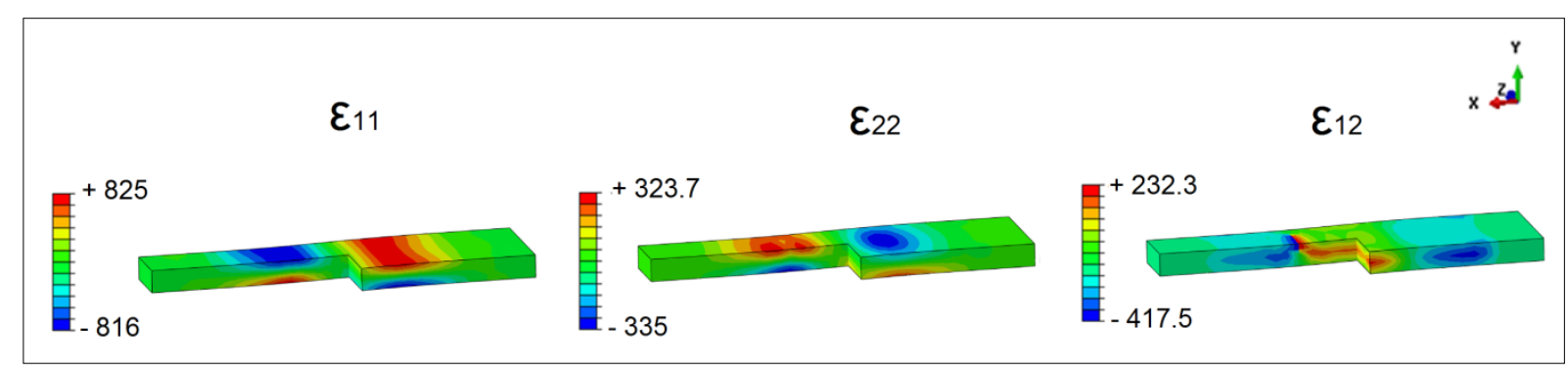

Fig. 7. Distribution of stresses on the PVC foam beam:

a) 3-point bending b) 4-point bending $\mathrm{A}$ c) 4-point bending $\mathrm{B}$ 




Fig. 8. Distribution of the strain $\varepsilon_{x x}$ in the section of the test specimen at $\mathrm{x}=400 \mathrm{~mm}$ for the 3 -point bending test 


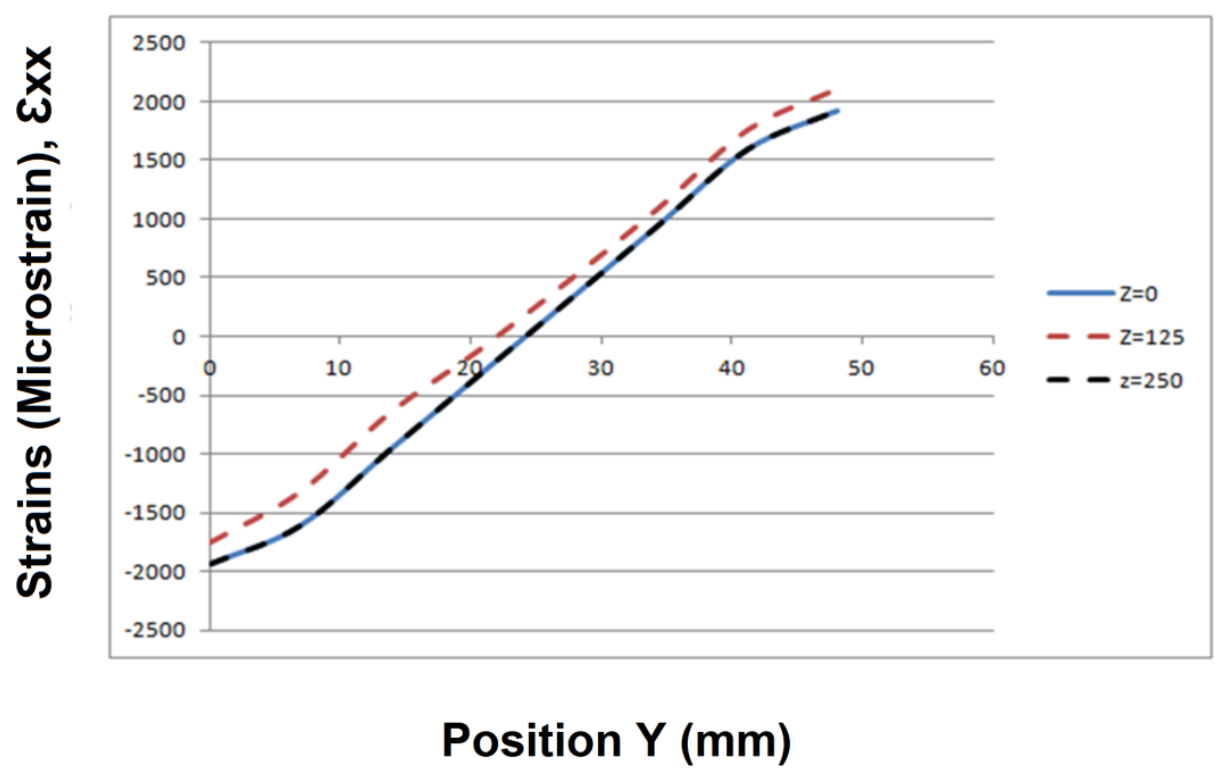

Fig. 9. Variation of the distribution of the $\varepsilon_{x x}$ deformations in the section for a 3-point bending test 
a)

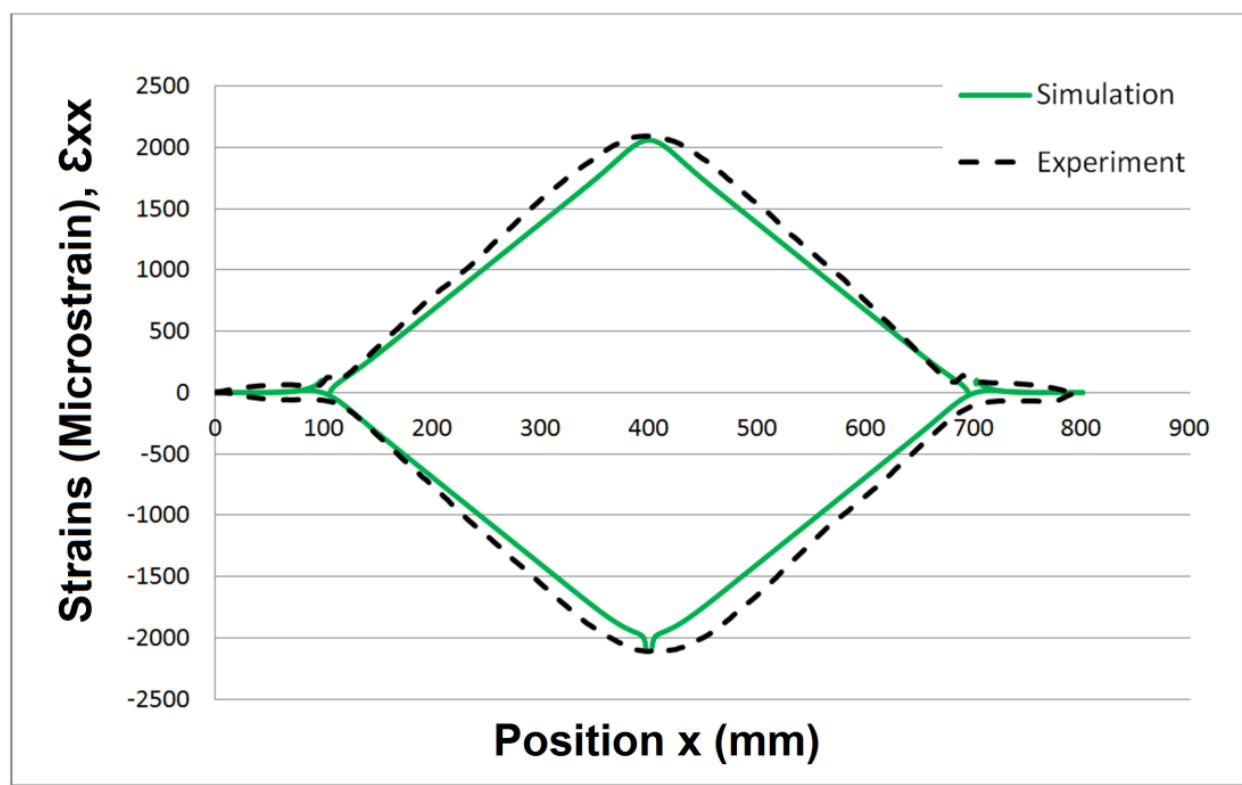

b)

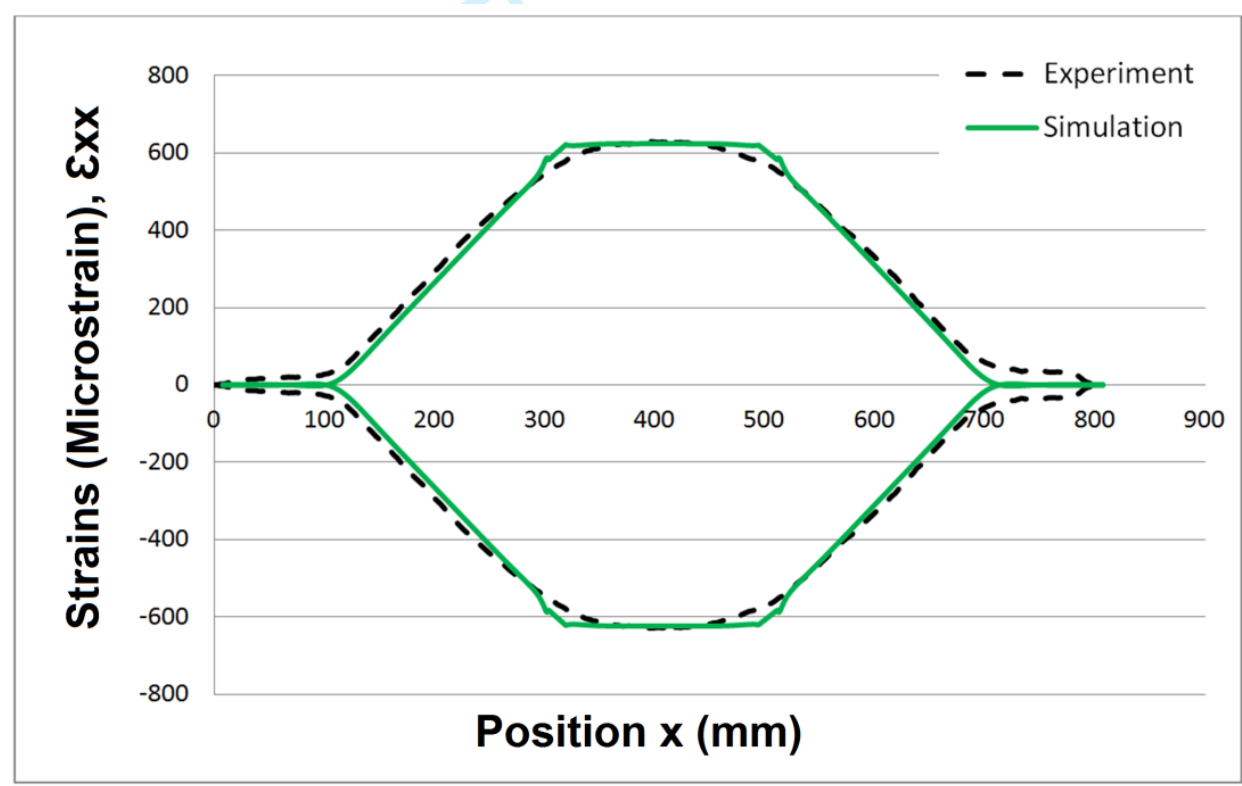


c)

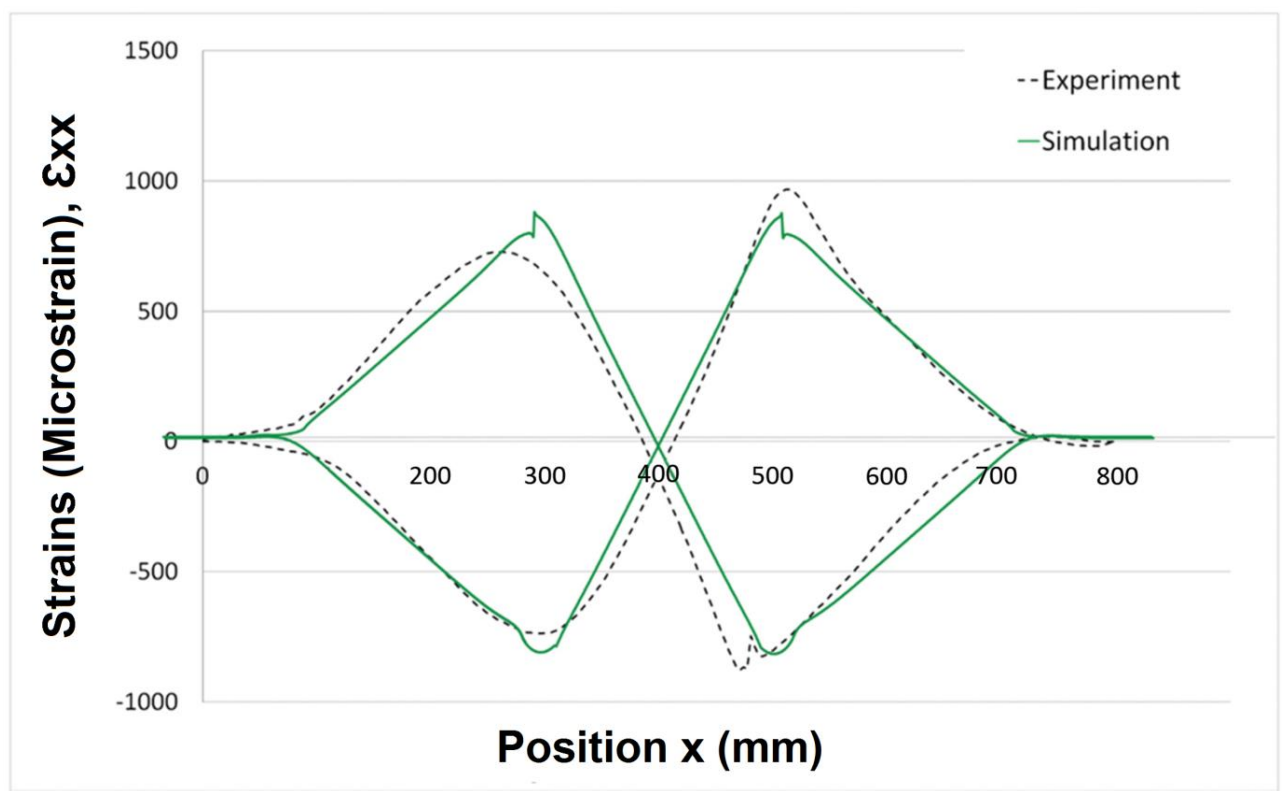

Fig. 10. Strain components located along the straight optical fiber a) 3-point bending, b) 4-point bending A c) 4-point bending $\mathrm{B}$ 


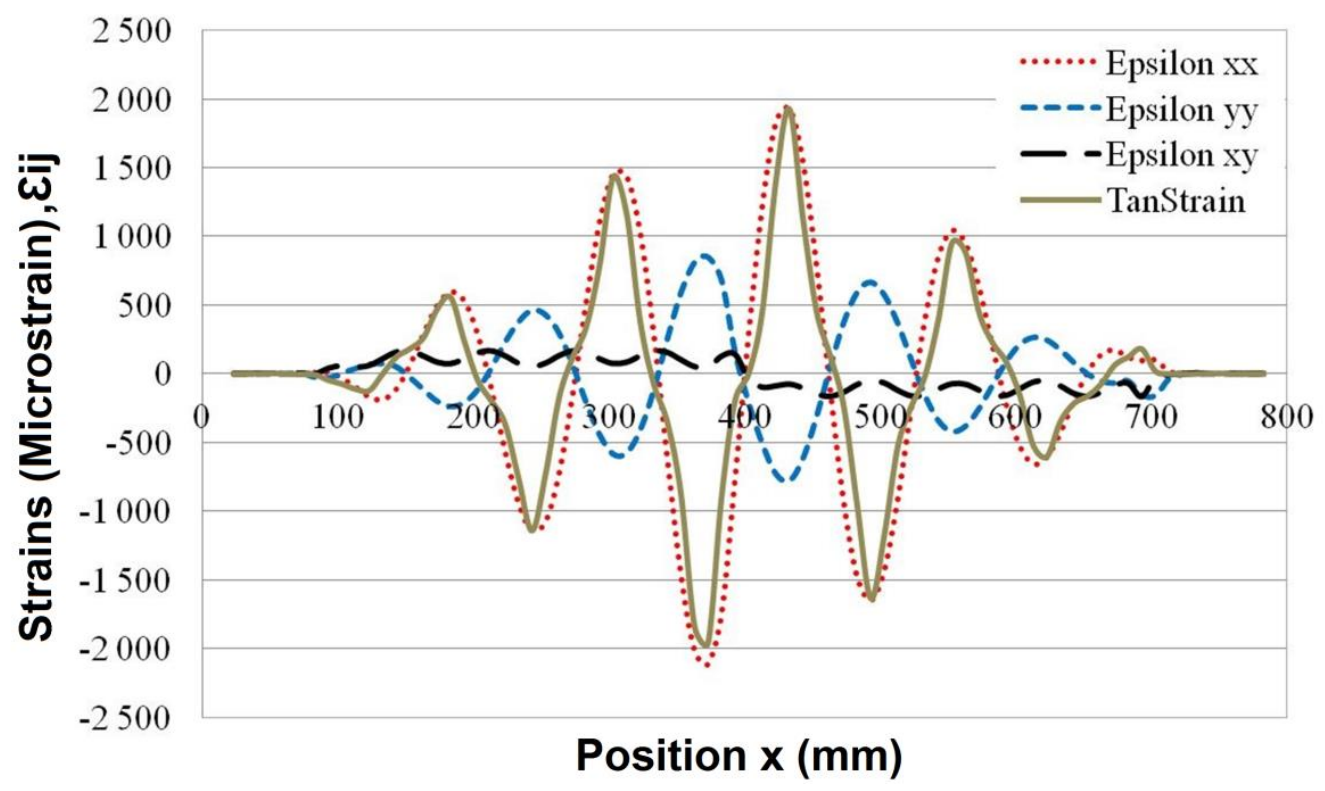

Fig. 11. Stress components located along the optical fiber. 
a)

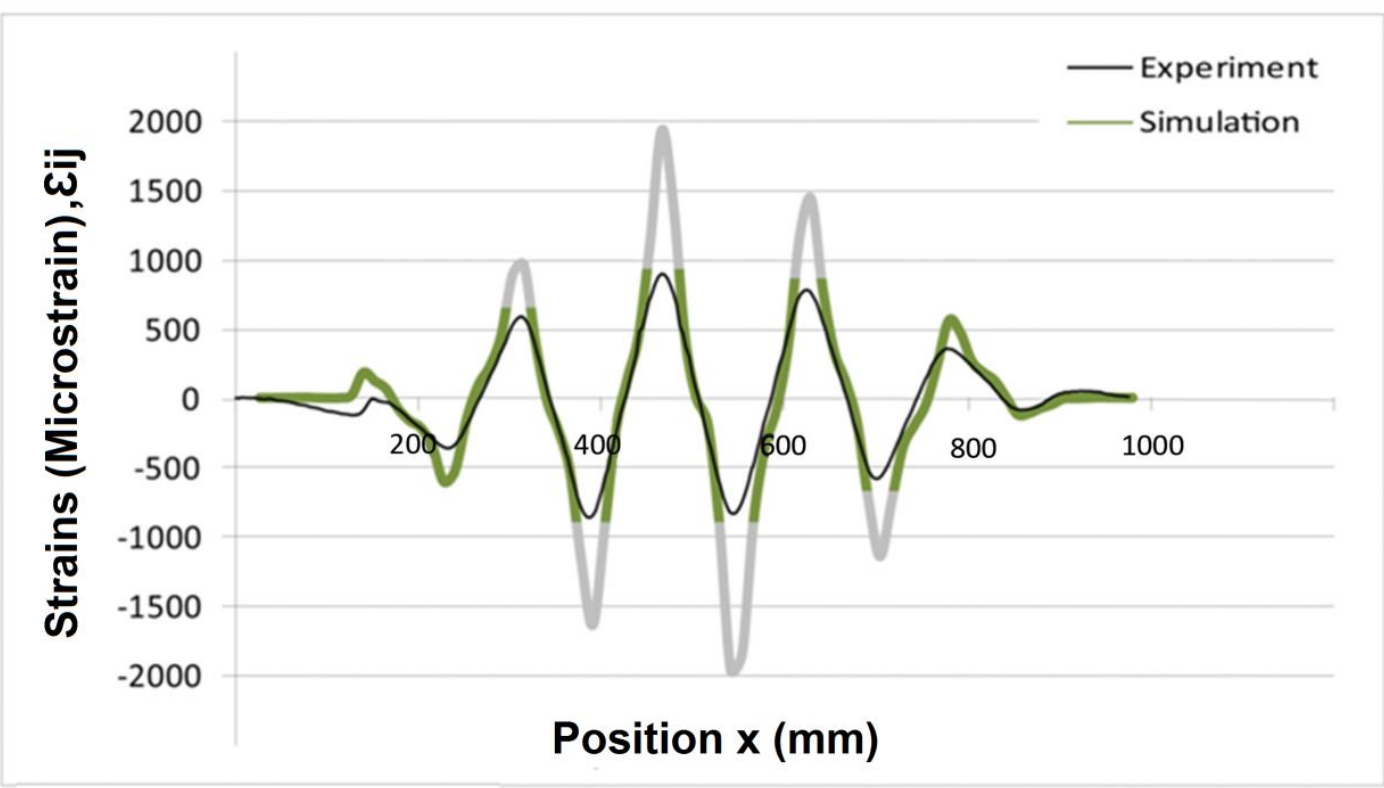

b)

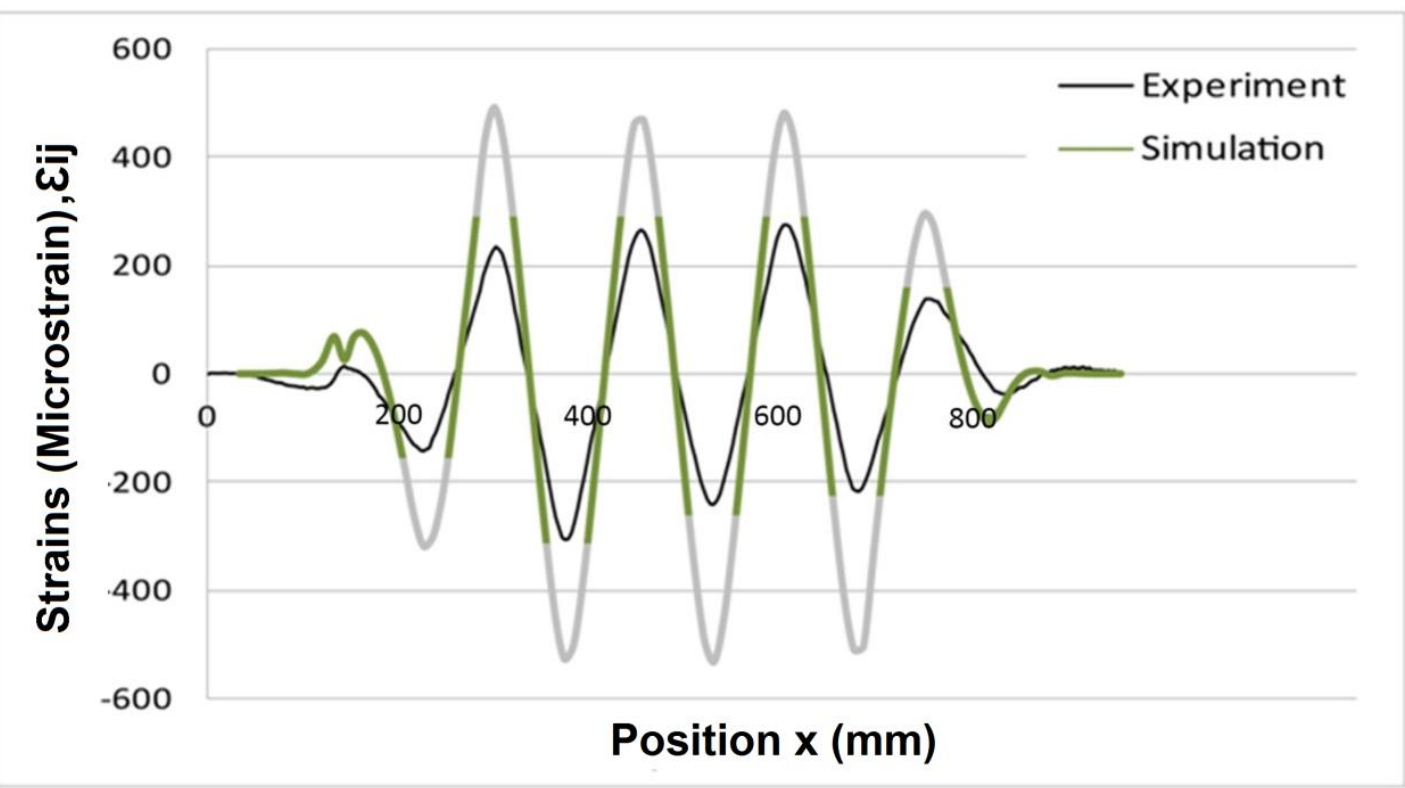


c)



Fig. 12. Strain components located along the undulated optical fiber a) 3-point bending test b) bending $4 \mathrm{~A}$ test and c) bending $4 \mathrm{~B}$ 